\title{
Antena Bikonikal Tabung untuk Aplikasi Radar Electronic Support Measures Dengan Pola Radiasi Omni-directional pada Frekuensi 2-18 GHz
}

\author{
Tube Biconical Antenna for Electronic Support Measures \\ Radar Applications With Radiation Pattern Omni-directional \\ on Frequency 2-18 GHz
}

\author{
Yussi Perdana Saputera *, Folin Oktafiani, dan Yuyu Wahyu \\ Pusat Penelitian Elektronika dan Telekomunikasi, Lembaga Ilmu Pengetahuan Indonesia. \\ Komp LIPI Gd 20, Jl Sangkuriang 21/54D, Bandung 40135, Indonesia
}

\begin{abstract}
Abstrak
Pada tulisan ini, dibahas hasil penelitian mengenai perancangan antena bikonikal tabung yang memiliki pola radiasi omnidirectional yang akan digunakan pada radar Elektronic Support Measures (ESM). Antena bikonikal memiliki karakteristik bandwidth yang sangat lebar (ultra wide band) cocok digunakan pada aplikasi ESM dengan frekuensi 2-18 GHz. Bentuk pola radiasi omni-directional yang dirancang bertujuan agar pada saat ESM melakukan deteksi frekuensi radar $(S$-, $C$-, $X$-, dan $K u$ band) dari pancaran radar yang berada di sekitarnya dapat melakukan deteksi ke segala arah. Karena kegunaan ESM sebagai detektor radar dengan sifat sebagai penerima (receiver) dibutuhkan VSWR di bawah 2,5 dengan nilai return loss di bawah 7,436. Antena bikonikal yang dirancang menggunakan dua plat tembaga yang dibentuk kerucut dengan penambahan tabung dengan pemasangan yang saling berhadapan, yang dipasang pada inner connector dan ground. Antena bikonikal dipasang mengunakan balun $1 / 4 \lambda$, agar matching impedansi antara antena dengan konektor $50 \Omega$. Plat tembaga yang digunakan dengan tebal $0,8 \mathrm{~mm}$.
\end{abstract}

Kata kunci: bikonikal, tabung, antena, omni-directional, ultra wide band.

\section{Abstrack}

The result of research on design of the biconical tube antenna which has omnidirectional radiation pattern to be used in radar ESM (Electronic Support Measures) is discussed in this paper. Biconical antenna has a very wide bandwidth characteristics (ultra wide band) suitable for use in ESM applications with frequency of 2-18 GHz. The designed omni directional radiation pattern shape has purpose so that when the ESM detects ( $S$-, $C$-, $X$-, and Ku-band) radar frequency of radar beam which exists in its vicinity, it can perform detection in all directions. Because the usefulness of ESM as a radar detector with nature as a receiver, it takes VSWR below 2.5 with return loss values below -7.436. Biconical antenna is designed using two copper plates with cone-shaped and the addition tubes which are installed facing each other, and mounted on inner connector and ground. Biconical antenna is installed using matching $1 / 4 \lambda$, so that impedance matching between the antenna and the connector is $50 \Omega$. Copper plate is used with the thickness of $0.8 \mathrm{~mm}$.

Keywords: biconical, tube, antenna. omni-directional, ultra wide band.

\section{Pendahuluan}

Electronic Support Measures (ESM) secara umum adalah sebuah peralatan elektronik yang berfungsi untuk menerima sinyal gelombang elektromagnetik, kemudian sinyal tersebut diproses dan dianalisa sehingga diperoleh lokasi (posisi), kuat sinyal (signal strength) dan parameter lainnya. Peralatan ESM seperti ditunjukkan dalam Gambar 1, terdiri dari bagian penerima, bagian prossesing dan mechanical support [1], [2].

Dalam tulisan ini, dilakukan perancangan dan simulasi mengenai antena omni-directional yang akan digunakan pada aplikasi ESM. Antena yang dirancang

\footnotetext{
* Corresponding Author.

Email: yussips@gmail.com

Received: May 30, 2013; Revised: June 28, 2013

Accepted: June 28, 2013

Published: June 30, 2013

(C) 2013 PPET - LIPI

doi: 10.14203/jet.v13.23-27
}

berbentuk bikonikal dengan tambahan tabung sebagai penambah gain. Antena bikonikal memiliki sifat dengan bandwidth yang lebar (ultra-wide-band) yang sangat cocok digunakan pada aplikasi ESM, yang dapat mencakup frekuensi $S$-band (2-4 GHz), C-band (4-8 GHz), X-band (9-12 GHz) dan Ku-band $(12-18 \mathrm{GHz})$ [3].
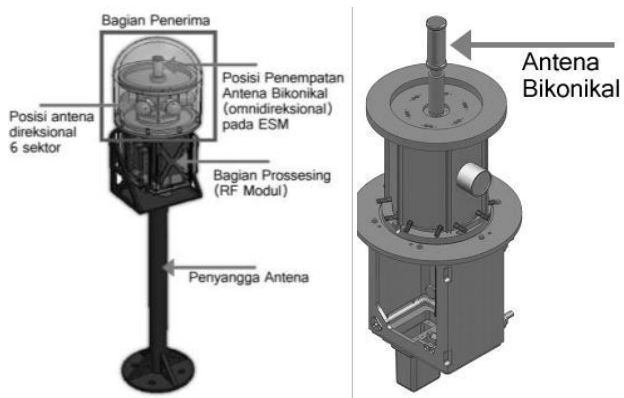

Gambar 1. Desain Posisi Antena Bikonikal Tabung pada Electronic Support Measures oleh PPET - LIPI[1], [2] 
Penelitian ini dikembangkan dari penelitian yang sudah dilakukan oleh industry telekomunikasi di negara lain. Tetapi produk yang ada dipasaran memiliki bentuk serta karekteristik yang kurang, sehingga tidak dapat digunakan pada aplikasi ESM. Mulai dari bentuk yang berbeda, VSWR yang masih tinggi, bandwidth yang sempit serta harga yang mahal [4], [5]. Oleh karena itu kami merancang antena bikonikal yang memiliki karekteristik yang dapat digunakan pada ESM serta harga yang relatif murah.

Tulisan ini terdiri dari 5 bagian pembahasan; bagian 1 berisi pendahuluan, bagian 2 berisi dasar teori yang menjadi landasan penelitian, bagian 3 berisi rancangan, simulasi dan hasil simulasi, bagian4 berisi analisa dan bagian 5 berisi kesimpulan dari penelitian yang telah dilakukan.

\section{DASAR TEORI}

\section{A. Antena ESM}

Antena ESM terdiri dari 2 buah antena yaitu omni dan directional, antena omni berfungsi untuk menerima sinyal dari keliling area $360^{\circ}$, kemudian oleh bagian penerima sinyal tersebut diproses (demodulasi) sehingga diperoleh parameter seperti jenis modulasi, frekuensi dsb. Antena directional terdiri dari 6 buah antena dipasang membentuk lingkaran sehingga diperoleh sudut $360^{\circ}$, masing masing antena mempunyai sudut $60^{\circ}$, dengan demikian fungsi antena ini hanya untuk menentukan arah atau lokasi dari sinyal yang diterima [1], [3].

\section{B. Antena Bikonikal}

Antena bikonikal merupakan antena yang memiliki bentuk yang terdiri dari 2 buah kerucut yang saling berhadapan antar masing-masing kerucut, dengan keunggulan dapat menghasilkan bandwidth yang lebar. Antena ini memiliki pola radiasi seperti koordinat bola, atau mengarah ke segala arah (omni-directional).

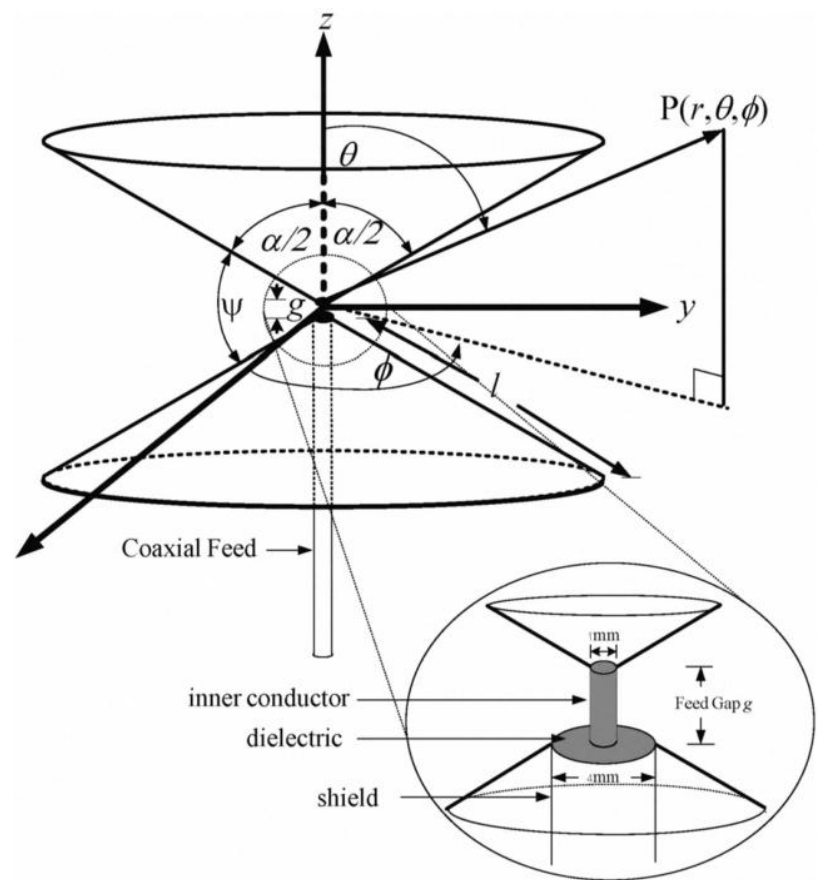

Gambar 2. Konfigurasi Catuan Antena Bikonikal [6].
Konfigurasi antena bikonikal mengunakan catuan kabel koaksial seperti dapat dilihat pada Gambar 2. Panjang cone pada antena bikonikal adalah $\boldsymbol{l}$. Radius kerucut $(r)$ pada antena bikonikal dicari menggunakan rumus:

$$
r=l \sin (\alpha / 2)
$$

Radius bagian cone bawah memiliki diameter sebesar jari-jari dari kabel koaksial, sudut antara dua kerucut adalah $\psi$. Kerucut atas dan bawah disusun simetris. Kerucut disusun dengan posisi kerucut saling berhadapan, dengan dipisahkan gap.

Untuk $(\alpha / 2)$ mempunyai nilai $30^{\circ}$ [1], sedangkan untuk nilai $\mathrm{r}$ didapat dari $\mathrm{r}=l / 2$, di mana $l$ merupakan panjang total.

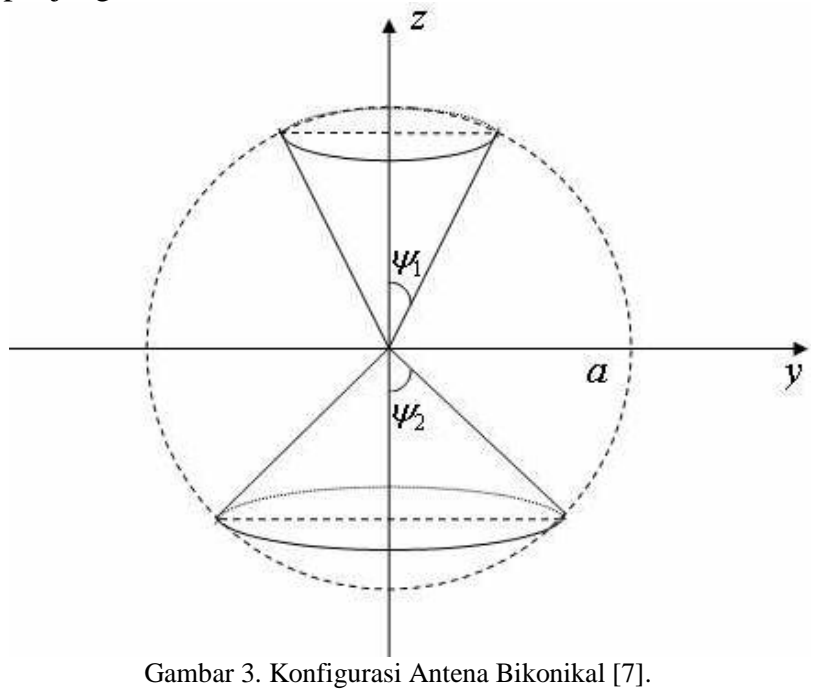

Gambar 3 adalah merupakan antena bikonikal berbentuk sebuah bola yang menutupi antena. [ $a$ mewakili panjang kerucut, $\psi_{1}$ dan $\psi_{2}$ mewakili setengah sudut kerucut antena bikonikal].

Struktur antena dapat dilihat pada Gambar 3. Hal ini secara aksial simetris dan memiliki sudut cone lebar dengan sudut setengah cone melebihi $40^{\circ}$. Setengah sudut cone $\psi_{1}$ dan $\psi_{2}$, dengan syarat memenuhi :

$$
0<\psi 1<\pi / 2
$$
dan,

$$
0<\psi 2 \leq \pi-\psi 1
$$

Bentuk cone simetris dengan cone lainnya.

Impedansi input antena dengan panjang cone dan sudut cone $\alpha$ pada antena bikonikal menggunakan formula sebagai berikut [8]:

$$
Z_{\text {in }}=Z_{o} \frac{1-\beta / \delta}{1-\beta / \delta}
$$

di mana,

$$
\begin{aligned}
& Z_{o}=60 \ln \operatorname{Cos}\left(\frac{\propto}{4}\right) \\
& \frac{\beta}{\delta}=e^{-2 j k l} \frac{\left.1+j \frac{60}{Z_{0}} \sum_{n=1}^{\infty} \frac{2 n+1}{n(n+1)}\left[P_{n}(\cos (\propto / 2))\right)\right]^{2} \zeta \mathrm{n}(k l)}{\left.-1+j \frac{60}{Z_{0}} \sum_{n=1}^{\infty} \frac{2 n+1}{n(n+1)}\left[P_{n}(\cos (\propto / 2))\right)\right]^{2} \zeta \mathrm{n}(k l)}
\end{aligned}
$$

di mana:

$$
\zeta \mathrm{n}(k l)=\frac{h_{n}{ }^{2}(k l)}{h_{n-1}{ }^{(2)}(k l)-\frac{n}{k l} h_{n}{ }^{(2)}(k l)}
$$


Keterangan :

$$
\begin{aligned}
& k=2 \pi \lambda, \lambda=\text { Panjang gelombang di ruang bebas, } \\
& Z_{0} \quad=\text { Karakteristik impedansi antena, } \\
& P_{n} \quad=\text { Legend repolinomial sebanyak n, } \\
& \zeta_{n}(k l) \quad=\text { Fungsi tambahan kompleks variable } \\
& \text { real } k l \text {, } \\
& h_{n}^{(2)} \quad=\text { Fungsi Hankel bola dari pangkat 2, } \\
& \beta / \delta=\text { Rasio antara penyebaran TEM }
\end{aligned}
$$

\section{DESAIN DAN SIMUlaSI}

Dalam penelitian ini, material yang digunakan adalah plat tembaga yang banyak dijual di pasaran, dengan ketebalan plat $0,8 \mathrm{~mm}$. Desain antena dapat dilihat seperti Gambar 4. Desain antena yang dilakukan dengan menambahkan tabung pada bagian atas cone, hal ini bertujuan untuk menurunkan nilai VSWR menjadi di bawah 2 .

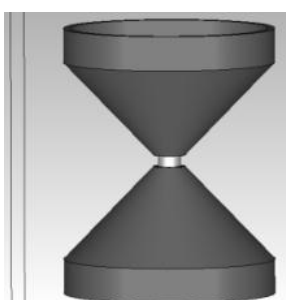

(a)

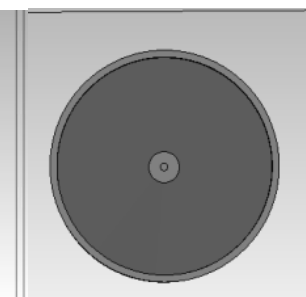

(b)
Gambar 4. Desain antena (a) Tampak samping, (b) Tampak atas.

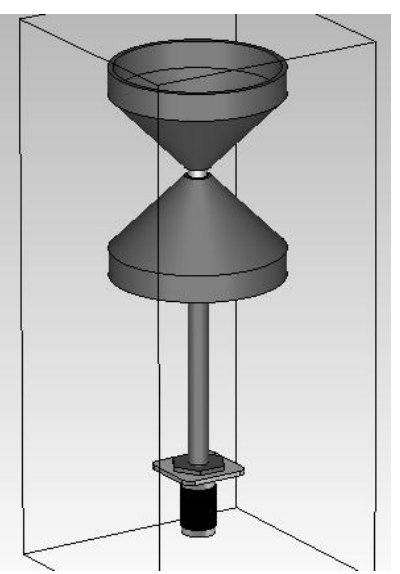

Gambar 5. Simulasi Antena Keseluruhan dengan Pencatuan 1/4 $\lambda$ dan Konektor Tipe N.

\section{A. S-Parameter}

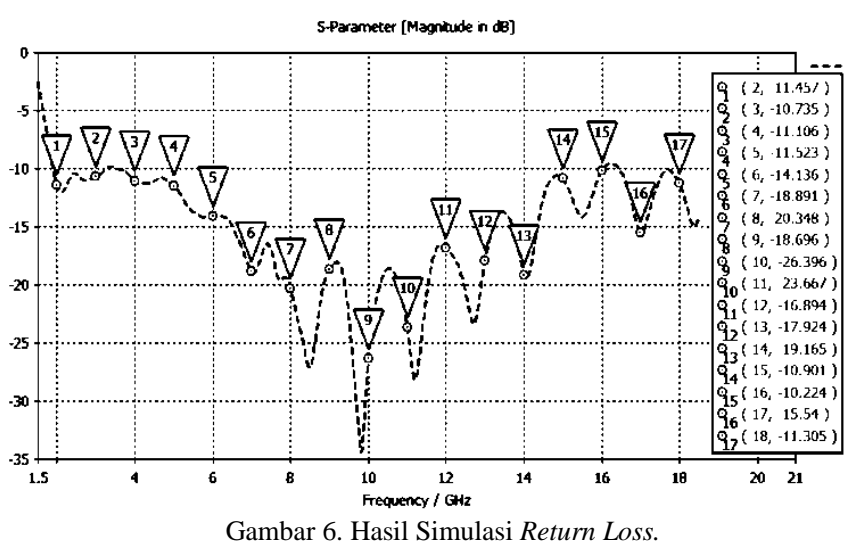

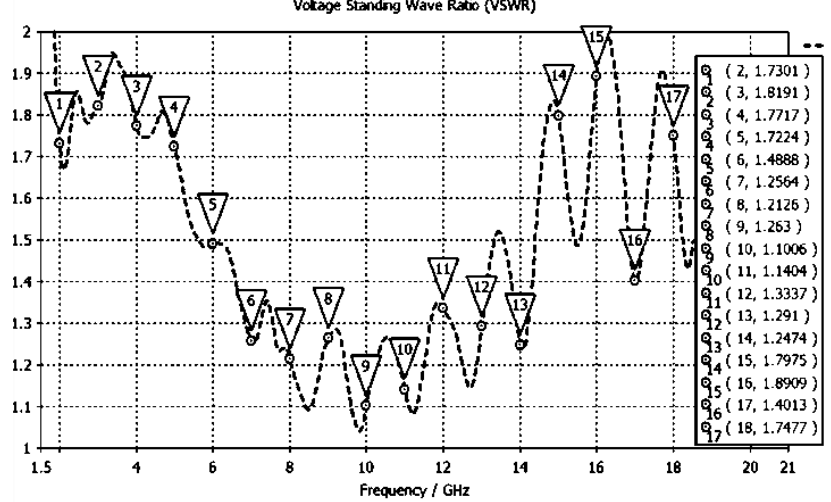

Gambar 7. Hasil Simulasi VSWR.

Dari simulasi yang dilakukan didapat nilai VSWR di bawah 2, serta memiliki VSWR yang bagus pada resonan frekuensi tengah untuk radar, yaitu:

TABEL I

HASIL SIMULASI S-PARAMETER PADA RESONAN FREKUENSI RADAR

\begin{tabular}{|c|c|c|c|}
\hline Band & Frekuensi & VSWR & Rerturn Loss \\
\hline $\mathrm{S}$ & $3 \mathrm{GHz}$ & 1,8191 & $-10,735$ \\
\hline $\mathrm{C}$ & $6 \mathrm{GHz}$ & 1,4888 & $-14,136$ \\
\hline $\mathrm{X}$ & $10 \mathrm{GHz}$ & 1,1006 & $-26,396$ \\
\hline $\mathrm{Ku}$ & $15 \mathrm{GHz}$ & 1,798 & $-10,901$ \\
\hline
\end{tabular}

\section{B. Gain dan Pola radiasi}

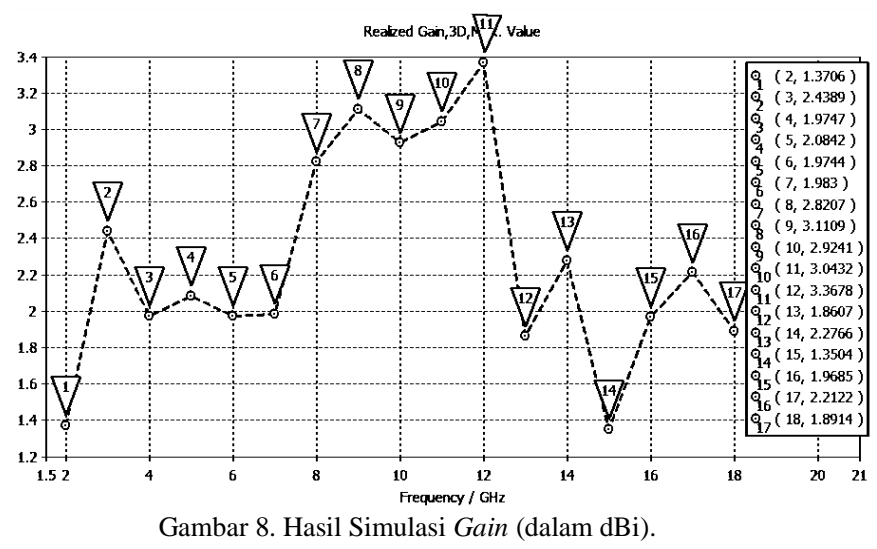

Dari simulasi didapatkan hasil gain keseluruhan (2$18 \mathrm{GHz}$ ) memiliki range mulai dari $1,3 \mathrm{dBi}-3,3 \mathrm{dBi}$.

TABEL II

HASIL SIMULASI GAIN PADA RESONAN FREKUENSI RADAR

\begin{tabular}{|c|c|c|}
\hline Band & Frekuensi & Gain \\
\hline $\mathrm{S}$ & $3 \mathrm{GHz}$ & 2,438 \\
\hline $\mathrm{C}$ & $6 \mathrm{GHz}$ & 1,973 \\
\hline $\mathrm{X}$ & $10 \mathrm{GHz}$ & 2,914 \\
\hline $\mathrm{Ku}$ & $15 \mathrm{GHz}$ & 1,350 \\
\hline
\end{tabular}

Dari Gambar 8 dan 9 dapat dilihat, bahwa gain yang dihasilkan relatif kecil. Hal ini dikarenakan, bentuk pola radiasi yang dihasilkan mengarah ke segala arah (omnidirectional). Daya yang disebarkan merata ke segala arah pancar yang ditimbulkan dari radiasi antena, yang sesuai dengan spesifikasi dari aplikasi ESM yang diinginkan. 


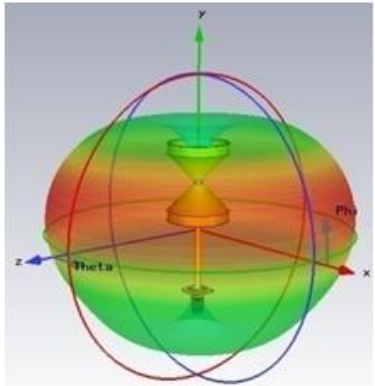

$\mathrm{S}-\operatorname{Band}(3 \mathrm{GHz})$

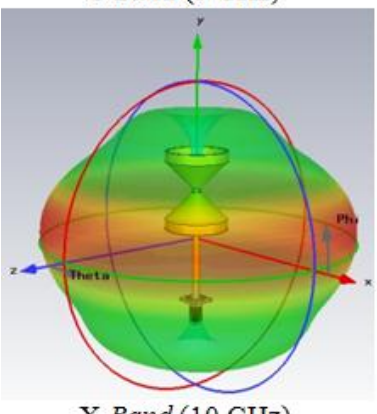

$\mathrm{X}$-Band (10 GHz)

Gambar 9. Hasil Simulasi Polarisasi Antena 3D.

Gambar 9 merupakan bentuk pola radiasi yang dihasilkan antena bikonikal tabung. Tiap-tiap frekuensi menghasilkan bentuk pola radiasi yang berbeda. Dalam hal ini mengambil frekuensi kerja radar.

\section{Sudut Theta dan Phi (2D)}

Sudut theta dan phi merupakan interpolasi yang didapat dari radiasi antena yang membentuk grafik 2 dimensi, sehingga dapat diketahui besaran sudut yang dihasilkan.

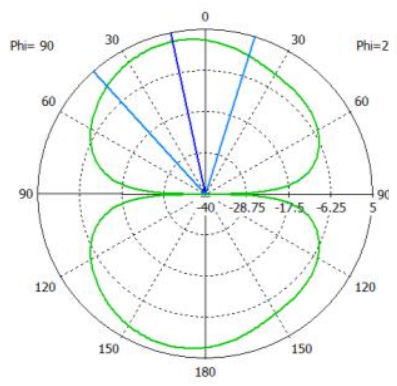

S-Band (3 GHz)

Main lobe magnitude $=2,4 \mathrm{~dB}$

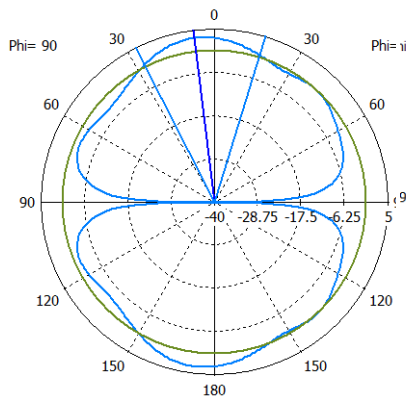

$X$-Band $(10 \mathrm{GHz})$

Main lobe magnitude $=2,9 \mathrm{~dB}$

Gambar 10. Hasil Simulasi Sudut Theta $90^{\circ}$ (2D)/Sudut Azimut

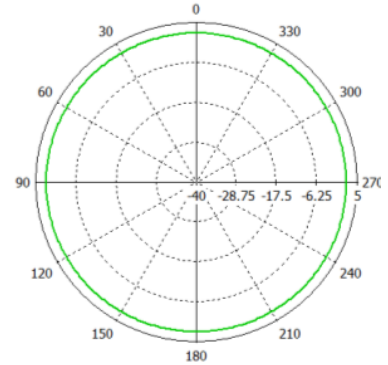

$S$-Band $(3 \mathrm{GHz})$

Main lobe magnitude $=1,9 \mathrm{~dB}$

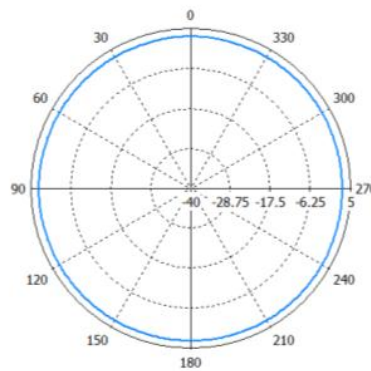

$X$-Band $(10 \mathrm{GHz})$

Main lobe magnitude $=2,6 \mathrm{~dB}$

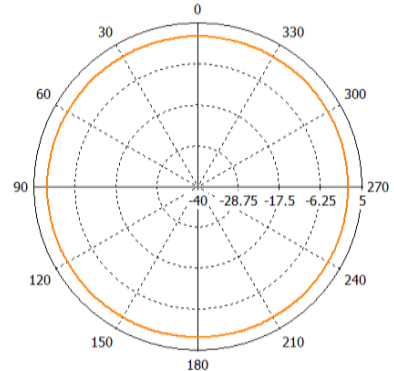

Main lobe magnitude $=1,1 \mathrm{~dB}$

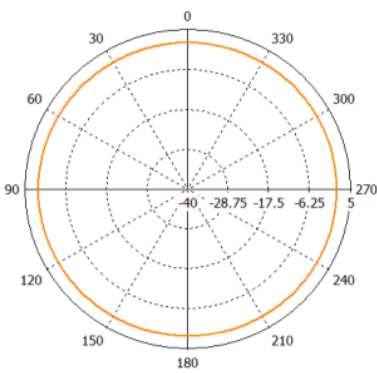

Ku-Band (15 GHz)

Main lobe magnitude $=1,1 \mathrm{~dB}$
Gambar 11. Hasil Simulasi Sudut Phi $0^{\circ}$ (2D)/Sudut Elevasi

Gambar 11 menggambarkan bahwa pola radiasi dari antena yang dirancang menghasilkan pola radiasi yang mengarah ke segala arah (omni-directional), dengan level magnitude yang berubah-ubah di masing-masing frekuensi (2-18 GHz).

\section{Polarisasi Antena}

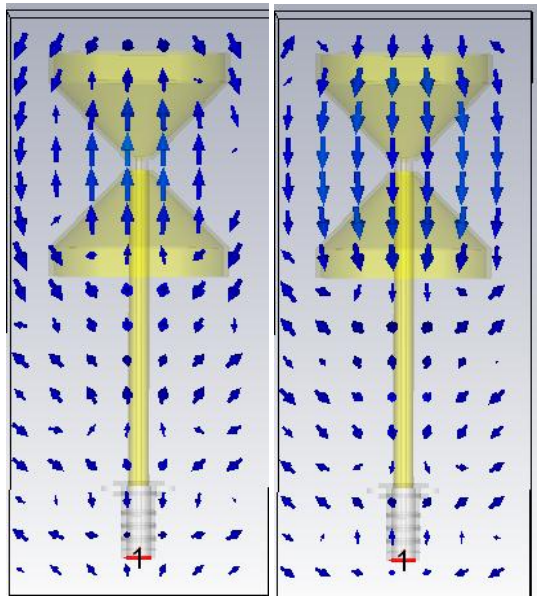

(a)

(b)
C-Band $(6 \mathrm{GHz})$

Gambar 12. Hasil Simulasi Polarisasi Antena, (a) Mengarah ke Atas, (b) Mengarah ke Bawah.

Gambar 12 menggambarkan hasil polarisasi dari antena bikonikal yang dirancang adalah linier vertikal.

\section{E. Medan-E dan Medan-H}

Medan-E (elektrik) dan medan-H (magnet) merupakan medan yang dihasilkan dari catuan daya yang ada pada antena. 


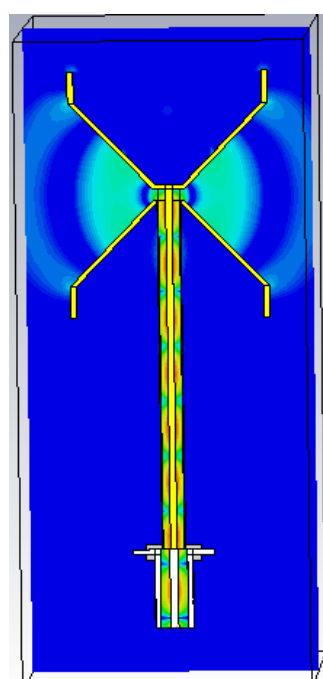

(a)

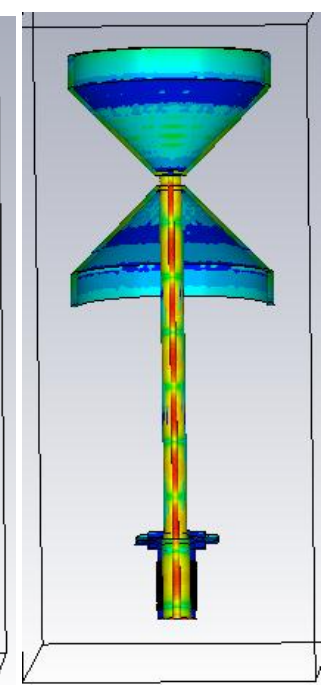

(b)
Gambar 13. Hasil Simulasi Medan E dan Medan H, (a) Bagian Luar, (b) Bagian Dalam.

\section{AnAlisa}

\section{A. Tinggi Cone}

Tinggi cone berpengaruh pada hasil optimasi $S$ parameter, semakin tinggi cone, nilai $S$-parameter yang dihasilkan akan semakin tidak bagus. Tetapi nilai optimum dari tinggi cone berada pada $15,5 \mathrm{~mm}$ pada setiap frekuensinya. Percobaan yang dilakukan dengan mengubah tinggi cone mulai dari $11 \mathrm{~mm}$ ke $23 \mathrm{~mm}$, dengan jarak 1 mm ditunjukkan pada Gambar 14.

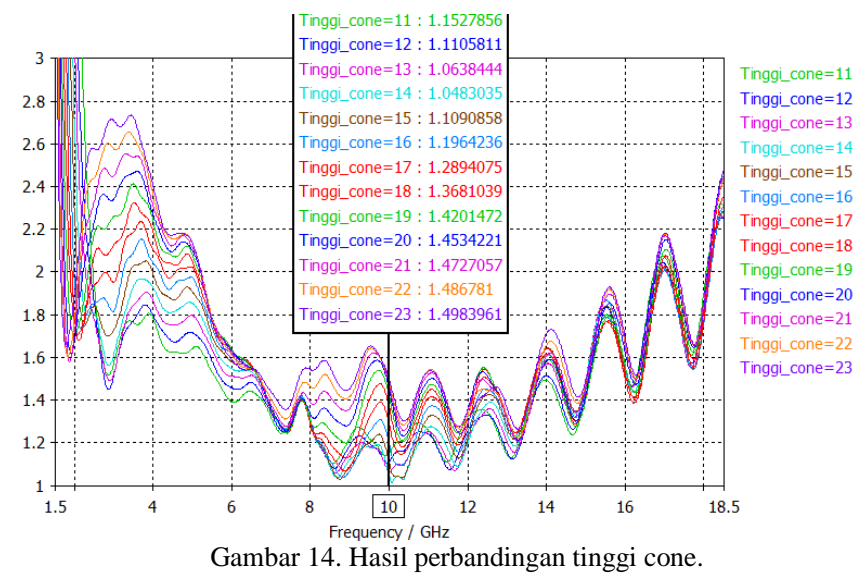

\section{B. Panjang Balun}

Panjang balun memiliki ukuran $1 / 4 \lambda$, yang bertujuan untuk menyepadankan impedansi antena dengan impedansi catuan. Panjang balun/saluran transmisi pada antena haruslah benar-benar $1 / 4 \lambda$, sehingga $S$-parameter mendapatkan hasil pada posisi yang paling optimum. Dalam penelitian ini panjang balun yang paling optimum berukuran $63 \mathrm{~mm}$, dengan VSWR 1,01 pada frekuensi center simulasi $(10 \mathrm{GHz})$. Hasil optimasi panjang balun/saluran transmisi ditunjukkan pada Gambar 15 .

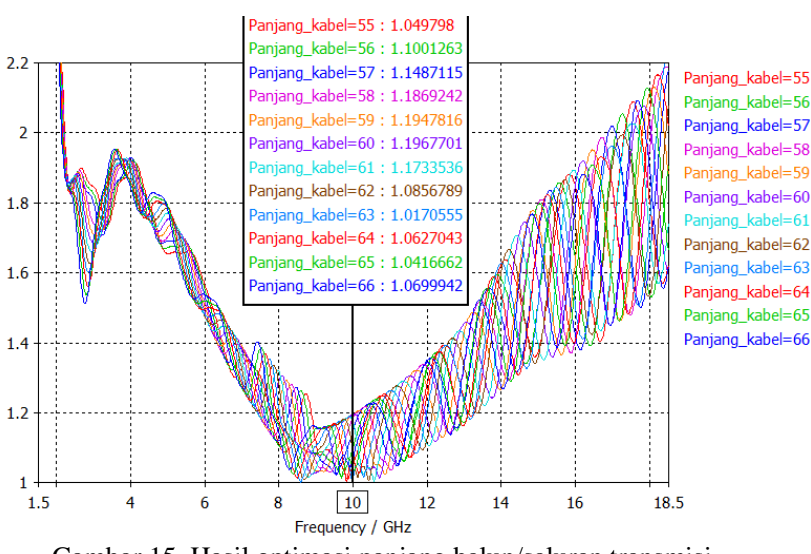

Gambar 15. Hasil optimasi panjang balun/saluran transmisi.

\section{KESIMPULAN}

Dari penelitian yang dilakukan, antena bikonikal terbukti mempunyai karekteristik bandwidth yang lebar dan nilai VSWR-nya mampu di bawah 2, pada frekuensi 2-18 GHz. Selain itu pola radiasi antena bikonikal berbantuk omni-directional pada semua resonan frekuensi yang disimulasikan, sehingga dapat memenuhi spesifikasi antena pada ESM.

\section{Daftar Pustaka}

[1] M. Wahab, Y. Wahyu, D. Ruhiyat, dan D. Permana, "Perbaikan, pembuatan RF head dan pembuatan electronic support measure (ESM)", PPET LIPI, Bandung, 2012.

[2] M. Wahab, D. Rudiyat, A. B. Santiko, dan N. D. Susanti, "Research and development on $\mathrm{rf}$ head and baseband pocessing of electronik support measure (ESM)", in Proc. ICRAMET, Surabaya, 2013, pp. $90-94$.

[3] Y. P. Saputera, Y. Wahyu, dan M. Wahab, "Spiral antena for electronic support measures (ESM) application 2-18 GHz", ICRAMET, Surabaya, 2013, in Proc. ICRAMET, Surabaya, 2013, pp. $35-39$.

[4] (2013) Antena biconical. [Online].Available: http://www.ainfoinc.com/en/pro_pdf/new_products/antena/BiConical\%20Antena/tr_SZ-20300.pdf

[5] (2013) Biconical antenna : ETS Lindgren. [Online]. Available: http://www.ets-lindgren.com/manuals/3104C.pdf

[6] R. Kudpik, K. Meksamoot, N. Siripon, and S. Kosulvit, Design of a Compact Biconical Antenna for UWB Applications, ISPACS, 2011.

[7] D. Ghosh, T. K. Sarkar, and E. L. Mokole "design of a wideangle biconical antena for wideband communications", Progress In Electromagnetics Research B, vol. 16, pp 229-245, 2009.

[8] C. H. Papas and R. W. P. King, "Input impedance of wide angle conical antenas fed by a coaxial line," Proc. IRE, vol. 37, pp 1269-1271, Nov. 1949. 